\title{
History of Medicine
}

\section{The history of sneezing}

\author{
J.J.M. Askenasy
}

Department of Neurology, Sheba Medical Center, affiliated to Sackler School of Medicine, Tel-Aviv University, Tel Hashomer 52621, Israel.

We are accustomed to thinking of the history of medicine as representing an ascendent line towards progress with its repetitive nature depicting it as an uninterrupted spiral. The history of sneeze is however neither of these but rather represents a closed circle.

In the Talmudic text, the Mishnah, 'sneeze' was described as a dialectic summation of a thesis and antithesis - combining the bad with the good. Sneezing in this concept means a unity of the bad, fearful omen and the good 'salvation'. Sneeze is permanently threatening to life and victorious over death. The custom of saying 'life' upon hearing someone sneeze, in order to thank God for remaining alive, originates in the Talmud. ${ }^{1,2}$ In Pliny 28:5 sneezing at the table carries the risk of death by choking. The Babylonian Talmud (Tractact Niddah 9:8) points out that sneezing in women is a sign of impending menstruation.

In Tractact Berachot 57B and Job 41:10 sneezing signifies the sprouting of light. In the first, sneezing is described as one of the six bodily functions which help the sick. In Kings $4: 35$, the son of the Shunamite woman, who appeared to have died of sunstroke, sneezed seven times and opened his eyes.

The Greek philosophers of the fourth century BC emphasized the holiness of sneezing considering it to be a divine sign of great importance (Ton Ptarmon Theon Egoumetha Einai: Problem, section 33:7). ${ }^{2,3}$ They raised the question as to why the other types of air that emanate from the body, namely flatus and ructus, are not considered to be holy. They rationalized that only sneezing comes from the principal and most divine organ - the container of the spirit. ${ }^{2}$

Between the years 460-377 Hippocrates attributed the same dialectic dualistic interpretation to sneezing. He claimed that sneezing was dangerous before or after a lung illness, but was beneficial to other diseases (Prognosticon 41:22). ${ }^{4}$ In the first century BC, Discorides reported the dangerous

Correspondence: J.J.M. Askenasy, M.D., Ph.D.

Accepted: 19 January 1990 relationship between epileptic seizures and copious sneezing. ${ }^{4}$ Hippocrates wrote in Aphorisms section 6:13 that 'Sneezing, in the case of a person afflicted with hiccup, cures the hiccup'. This true feature was understood 2,000 years later by means of the reciprocal inhibition phenomenon. ${ }^{4}$ Celsus emphasized the beneficial aspect of sneezing during convalescence from illness (Medic 2:3). This belief still exists today among the Zulu tribes. ${ }^{5}$

During the Middle Ages the history of sneeze received the well known mystic aura of the period. Its ominous threat located the sneeze as being close to evil. ${ }^{6}$ The negative aspect of the sneeze gained strong momentum by the Bubonic Plague which afflicted Rome in the period 590-610. In this epidemic, people suddenly died while sneezing. The need to prevent it led to the custom of calling out 'deus te adjuvet' to someone who sneezed, thereby displaying signs of affliction. Pope Pelagius II died in this epidemic while sneezing. From this period on, the blessing attached to the sneeze became imperative. ${ }^{1}$ Pope Gregory VII enjoined his people to say, 'may God bless you' as an equivalent to 'I hope you may rid yourself of the bacillus'. The Romans used the blessing 'salve' meaning good health to you. 'Prosit', 'bless you' or 'zur Gesundheit' are blessings dating from the same period. Jewish mothers, on hearing a child sneezing, proclaim the blessing 'to health' and pull up the child's ear, thereby averting an unknown catastrophe. On the second sneeze, the other ear will be pulled up accompanied by the blessing 'to grow and thrive'.

The strong mystic influence of the Middle Ages on the history of sneeze persists even today in various cultures. Persian demonology and Roman culture bless the sneezer. The Romans used the term 'Absit omen', meaning 'evil spirit be gone'. 1.7

In contrast to the Middle Ages' negative approach, we learn that the Indian people were grateful and satisfied when they sneezed and were worried if they discovered that they were unable to sneeze. This belief remained at the base of the Indian habit of using herbal concoctions for the nose, in order to provoke nasal drainage through sneezing. ${ }^{8-10}$ Naswar Sunghani is a snuff of refined tobacco which produces explosive sneezing. The 
basis of the concept of a sneeze confirming the 'truthfulness' of a tale is related to the Indian culture.

This belief was immortalized by the Hungarian composer Zoltan Kodaly in 'The Harry Janos Suite' which opens with a huge orchestral sneeze, confirming a hunting tale as being truthful. ${ }^{1}$

The modern scientific approach presents the

\section{References}

1. Kavka, S.J. The sneeze - blissful or baneful? JAMA 1983 249: 2305-2306.

2. Rosner, F. The sneeze (Letter). JAMA 1983, 250: 3280.

3. Rosner, F. Julius Preuss' Biblical and Talmudic Medicine. New York Hebrew Publishing Co., New York, 1978 pp. 74-76.

4. Adams, F. The genuine works of Hippocrates. Williams and Wilkins, Baltimore, 1939, p. 314

5. Tylor, S. Anfange der Kultur, Vol. I. Leipzig 1873, p. 98.

6. Graner, J. The Sneeze (Letter). JAMA 1983, 250: 3280.

7. Leach, M. The Standard Dictionary of Folklore, Mythology and Legend. Fund \& Wagnalis, New York, 1960, p. 2. same dialectic duality in the understanding of the sneeze. When isolated, the sneeze is a physiological defence reflex by which we eliminate foreign undesirable material from the nasal cavity. When repetitive, it is a sign of a pathological process and is considered a threat. It is at this point that the historical circle of sneeze closes.

8. Mora, G. Historical and theoretical trends in psychiatry. In: Kaplan, H.I., Freedman, A.M. \& Sadock, N.J. (eds) Comprehensive Textbook of Psychiatry, vol. I, third edition. Williams \& Wilkins, Baltimore, 1980.

9. Giel, R., Gezahegn, Y. \& Van Lnijk, J.V. Faithhealing and spirit possession in Ghion, Ethiopia. Soc Sci Med 1968, 2. 63-79.

10. Left, J.P. Psychiatry Around the Globe: a Transcultural View. Marcel Dekker, New York, 1981. 